\title{
PENINGKATKAN HASIL BELAJAR PKN KELAS V MELALUI MODEL ACTIVE LEARNING TIPE ROLE REVERSAL QUESTION
}

\author{
Ambar Susilo Murti \\ SD Negeri 4 Doplang Kecamatan Jati, UPT TK/SD Kecamatan Jati Kabupaten Blora \\ Email: ambar5215@gmail.com
}

\begin{abstract}
Abstrak
Undang-Undang Nomor 20 Tahun 2003, tentang Pendidikan Kewarganegaraan (PKn) merupakan mata pelajaran wajib untuk jenjang pendidikan dasar, menengah, dan mata kuliah wajib untuk pendidikan tinggi. Tujuan penelitian ini adalah meningkatkan hasil belajar PKn dengan menggunakan Model Active Learning Tipe Role Reversal Question pada siswa kelas V SDN 4 Doplang Kecamatan Jati Kabupaten Blora. Penelitian ini merupakan penelitian tindakan kelas (classroom action research). Adapun tahapannya sebagai berikut: (1) perencanaan, (2) pelaksanaan, (3) pengamatan dan (4) refleksi. Hasil penelitian menunjukkkan bahwa siswa yang memperoleh nilai $\geq 70$ pada siklus I meningkat sebesar $25 \%$ dari kondisi awal $44 \%$ menjadi $69 \%$. Kemudian siswa yang memperoleh nilai $\geq 70$ pada siklus II mengalami peningkatan $28 \%$ menjadi $97 \%$. Nilai rata-rata pada siklus I mengalami peningkatan sebesar $8,75 \%$ dari kondisi awal 66,53 menjadi 75,28 pada siklus I kemudian pada siklus II nilai rata- rata mengalami peningkatan lagi sebesar $10,97 \%$ menjadi 86,25 . Peneliti menyarankan hendaknya guru dapat mendorong siswa agar lebih berani dalam mengemukakan pendapat, pertanyaan dan ide yang dimiliki tidak hanya dalam pelajaran PKn saja namun pada mata pelajaran yang lain. Selain itu, Guru diharapkan dapat menggunakan model active learning tipe role reversal question dalam meningkatkan hasil belajar siswa pada mata pelajaran lain. Adapun bagi pihak sekolah diharapkan memberikan pelatihan kepada guru tentang menerapkan kegiatan pembelajaran yang inovatif dan kreatif.
\end{abstract}

Kata Kunci: active learning, PKn, dan hasil belajar

\begin{abstract}
Abstrack
Constitution No. 20 of 2003, concerning Citizenship Education (PKN) is a compulsory subject for primary education, secondary, and compulsory subjects for higher education. The purpose of this study is to improve learning outcomes Civics using Active Learning Model Type Question Role Reversal in Class V SDN 4 Doplang Jati district of Blora. This research is a class action (classroom action research). The stages as follows: (1) planning, (2) implementation, (3) observation and (4) reflection. The result of research indicating that students who received grades $\geq 70$ the first cycle increased by $25 \%$ from the initial $44 \%$ to $69 \%$. Then students who scored $\geq 70$ on the second cycle increased $28 \%$ to $97 \%$. The average value of the first cycle increased by $8.75 \%$ from 66.53 into 75.28 early in the first cycle and then the second cycle of the average value increased again by $10.97 \%$ to 86.25 . Researchers suggest should teachers can encourage students to be more daring in expressing opinions, questions and ideas that are not held only in Civics alone
\end{abstract}


but on other subjects. In addition, teachers are expected to use active learning model of the type of role reversal question in improving student learning outcomes in other subjects. As for the school is expected to provide training to teachers on implementing learning activities are innovative and creative.

Keywords: active learning, civic education and learning outcomes

\section{PENDAHULUAN}

Proses pembelajaran PKn di sekolah dasar belum sepenuhnya melibatkan siswa secara aktif, seperti halnya yang terjadi pada kelas V SDN 4 Doplang Kecamatan Jati. Kegiatan pembelajaran masih di dominasi oleh aktivitas guru yaitu dengan pengunaan metode ceramah saat menjelaskan materi pelajaran. Berdasarkan observasi yang dilakukan pada saat kegiatan pembelajaran PKn berlangsung, siswa tidak sepenuhnya memperhatikan penjelasan guru, dikarenakan bosan dengan aktivitas mendengarkan, sehingga pembelajaran PKn dirasa kurang menyenangkan bagi siswa.

Keadaan tersebut menimbulkan pemerolehan hasil belajar yang belum masimal. Rendahnya hasil belajar Pkn dapat dilihat dari data nilai semester I tahun ajaran 2016/2017. Rata-rata nilai PKn lebih rendah dibandingkan nilai Bahasa Indonesia dan IPS. Diketahui bahwa nilai rata-rata Bahasa Indonesia 74, IPS 68, dan PKn 66. Selain nilai rata-rata PKn rendah diperoleh data bahwa baru 18 siswa atau 50\% dari jumlah siswa yang belum memenuhi KKM yang ditentukan yaitu 65. Melihat jumlah siswa yang masih banyak memperoleh nilai dibawah kriteria ketuntasan dan rata-rata nilai PKn yang belum maksimal maka perlu dilakukan peningkatan hasil belajar PKn.

Model pembelajaran yang dapat diterapkan utnuk mengatasi permaslahan tersebut adalah model active learning atau model pembelajaran aktif. Active learning atau pembelajaran aktif merupakan model pembelajaran yang mengacu pada tujuan pembelajaran, melibatkan siswa, menggunakan seni, gerakan dan panca indera serta langkah dan kegiatan dalam pembelajaran (Hollingsworth, Pat \& Gina Lewis, 2008). Model pembelajaran aktif (active learning) bertujuan untuk membuat aktif dalam aktivitas belajar. Menurut Silberman (2007) 
menyebutkan ada 101 pembelajaran aktif salah satunya role reversal question. Role reversal question merupakan kegiatan pembelajaran aktif yang menekankan pada aktivitas tanya jawab dengan pertukaran peran. Jika guru bertukar peran menjadi siswa maka guru mengajukan pertanyaan dan siswa mencoba menjawab pertanyaan. Begitu pula sebaliknya jika siswa yang mengajukan pertanyaan maka guru yang menjawab.

Sesuai dengan identifikasi masalah yang dikemukakan maka penelitian ini bertujuan untuk meningkatkan hasil belajar PKn dengan menerapkan Model pembelajaran Active Learning tipe Role Revesal Question di kelas V SD Negeri 4 Doplang, Kecamatan Jati Kabupaten Blora.

Hasil belajar menurut pemikiran Gagne (M.Thobroni \& Arik Mustofa, 2013) berupa informasi verbal, keterampilan intelektual, strategi kognitif, keterampilan motorik, dan sikap. Informasi verbal merupakan kemampuan dalam mengungkapkan pengetahuan baik dalam bentuk bahasa lisan maupun tertulis. Informasi tersebut harus tersampaikan dengan baik, salah satunya dengan menggunakan model pembelajaran yang sesuai dengan kebutuhan siswa.

Model pembelajaran merupakan prosedur dan dijadikan pedoman dalam perancangan pembelajaran. Salah satu model pembelajaran adalah model pembelajaran aktif (active learning) tipe role reversal question yang bertujuan untuk membuat aktif dalam aktivitas belajar. Adapun langkah-langkah pembelajaran model active learning tipe role reversal question menurut Silberman (2007) antara lain: a) susunlah pertanyaan yang akan anda kemukakan tentang materi pelajaran seolah-olah anda seorang peserta didik; b) pada awal sesi pertanyaan, umumkan kepada peserta didik bahwa anda akan menjadi peserta didik dan peserta didik secara kolektif menjadi anda. Beralihlah lebih dahulu ke pertanyaan anda; c) berlakukah argumentatif, humoris, atau apa saja yang dapat membawa mereka pada perdebaran dan menyerang anda dengan jawaban- jawaban; d) memutar peranan beberapa kali akan tetap membuat peserta didik anda pada pendapat mereka dan mendorongnya untuk melontarkan 
pertanyaan milik sendiri; e) langkah-langkah pembelajaran model active learning tipe role reversal question yang digunakan sesuai dengan pendapat di atas, namun ada beberapa hal yang disesuaikan dengan kemampuan dan kebutuhan siswa.

\section{METODE PENELITIAN}

Penelitian ini merupakan penelitian tindakan kelas (classroom action research). Menurut Arikunto,dkk (2007) penelitian tindakan kelas merupakan suatu pencermatan dari kegiatan pembelajaran berupa tindakan yang sengaja dimunculkan dan terjadi pada sebuah kelas secara bersama. Menurut Arikunto (2007) penelitian tindakan kelas dilakukan sekurang-kurangnya dalam dua siklus tindakan yang berurutan. Ada empat tahapan yang dilalui yaitu (1) perencanaan, (2) pelaksanaan, (3) pengamatan dan (4) refleksi.

Teknik pengumpulan data menggunakan instrumen tes dan instrumen non-tes. Instrumen tes digunakan untuk mengukur atau menilai hasil belajar (Muljono, 2008), sedangkan instrumen non-tes dilakukan dengan observasi, wawancara dan dokumentasi. Teknik analisis data menggunakan analisis deskriptif kuantitatif berupa hasil nilai tes siswa yang dianalisis dengan menggunakan teknik analisis deskriptif dengan menentukan mean atau rerata dan penyajian data kuantitatif dipaparkan dalam bentuk persentase.

Pelaksanaan penelitian tindakan kelas menggunakan tolak ukur indikator keberhasilan yang ditentukan dengan Kriteria Ketuntasan Minimal (KKM) yaitu $\geq 68$ yang dicapai siswa sebesar $70 \%$, dan nilai rerata kelas $\geq 83$ dari 36 siswa.

\section{HASIL PENELITIAN DAN PEMBAHASAN}

Data yang digunakan untuk menyatakan hasil belajar Matematika adalah nilai yang didapat oleh siswa pada tes evaluasi yang diadakan pada tiap akhir 
siklus. Hasil belajar PKn siswa kelas V disajikan pada Tabel 1.1 Daftar Nilai PKn kelas V berikut :

Tabel 1. Daftar Nilai PKn Kelas V

\begin{tabular}{lcccccc}
\hline & & \multicolumn{3}{c}{ Nilai PKn } & \multicolumn{2}{c}{ Keterangan } \\
\cline { 3 - 6 } No. & Rentang Nilai & Pra Siklus & Siklus I & Siklus II & Tuntas & $\begin{array}{c}\text { Tidak } \\
\text { Tuntas }\end{array}$ \\
\hline 1. & $\leq 37$ & - & - & - & - & $\sqrt{ }$ \\
2. & $38-47$ & 1 & - & - & - & $\sqrt{ }$ \\
3. & $48-57$ & 2 & 3 & - & - & $\sqrt{ }$ \\
4. & $58-67$ & 17 & 10 & 2 & - & $\sqrt{ }$ \\
5. & $68-77$ & 12 & 9 & 7 & $\sqrt{ }$ & - \\
6. & $78-87$ & 4 & 12 & 11 & $\sqrt{ }$ & - \\
7. & $88-97$ & - & 2 & 12 & $\sqrt{ }$ & - \\
8. & $98-100$ & - & - & 4 & $\sqrt{ }$ & - \\
\hline
\end{tabular}

Pada tahap pra tindakan yang diberikan oleh 36 siswa, diperoleh nilai ratarata hasil belajar sebesar 66,53. Jumlah siswa yang memperoleh nilai $\geq 68$ berjumlah 16 siswa atau 44\%, sedangkan 20 siswa atau 56\% dari jumlah siswa memperoleh nilai < 68. Hal tersebut menunjukkan bahwa hasil belajar siswa masih cukup jauh dari tujuan yang diharapkan. Untuk itu peneliti merasa perlu melakukan penelitian tindakan guna meningkatkan hasil belajar yang belum sesuai dengan harapan. Pada siklus I terjadi peningkatan rata-rata hasil belajar sebesar 8,75\% yaitu dari 66,53 pada kondisi awal menjadi 75,28. Jumlah siswa yang memperoleh nilai $\geq 68$ mengalami peningkatan sebesar $19 \%$ dari kondisi awal $44 \%$ menjadi $69 \%$. Hal ini membuktikan bahwa tindakan pada siklus I memiliki pengaruh terhadap hasil belajar siswa pada mata pelajaran PKn.

Kendala yang muncul pada siklus I diperbaiki pada siklus II. Pada siklus II guru menjelaskan kegiatan pembelajaran sesuai dengan rencana pelaksanaan pembelajaran yaitu pada awal kegiatan. Setelah siswa mengerti, kegiatan selanjutnya baru dilakukan. Guru selalu membimbing dan mengarahkan siswa dalam kegiatan pembelajaran. Guru juga memberikan dorongan serta motivasi kepada siswa agar aktif dalam pembelajaran. Sesuai dengan pendapat Sugihartono, dkk (2007) salah satu peran guru dalam kegiatan pembelajaran adalah sebagai motivator. Hasil pengamatan terhadap siswa pada siklus II menunjukkan bahwa siswa lebih aktif, senang dan bersemangat mengikuti 
pembelajaran. Setelah selesai berdiskusi siswa langsung meminta lembar untuk membuat pertanyaan individu dan sangat antusias untuk melakukan tanya jawab dengan bertukar peran. Pada saat tanya jawab dengan bertukar peran guru memberikan reward bagi siswa yang menjawab pertanyaan dengan benar, sehingga siswa berlomba-lomba untuk mendapatkan reward paling banyak.

Hasil belajar siswa setelah dilakukan perbaikan tindakan pada siklus II mengalami kenaikan secara signifikan dari pra siklus, siklus I dan sikus II. Nilai rata-rata hasil belajar siswa naik 8,75\% dari kondisi awal 66,53 menjadi 75,27 pada siklus I, dan meningkat lagi 10,97\% menjadi 86,25 pada siklus II. Siswa yang memperoleh nilai $\geq 68$ meningkat 19\% dari kondisi awal, 44\% menjadi $69 \%$ pada siklus I, dan meningkat lagi $28 \%$ menjadi $94 \%$ pada siklus II. Dengan demikian siklus II sudah mencapai kriteria keberhasilan yang ditentukan yaitu $75 \%$ dari jumlah siswa memperoleh nilai $\geq 70$, dan nilai rerata kelas $\geq 83$ sehingga penelitian berhenti pada siklus II. Peningkatan hasil belajar PKn disajikan pada gambar 1 berikut :

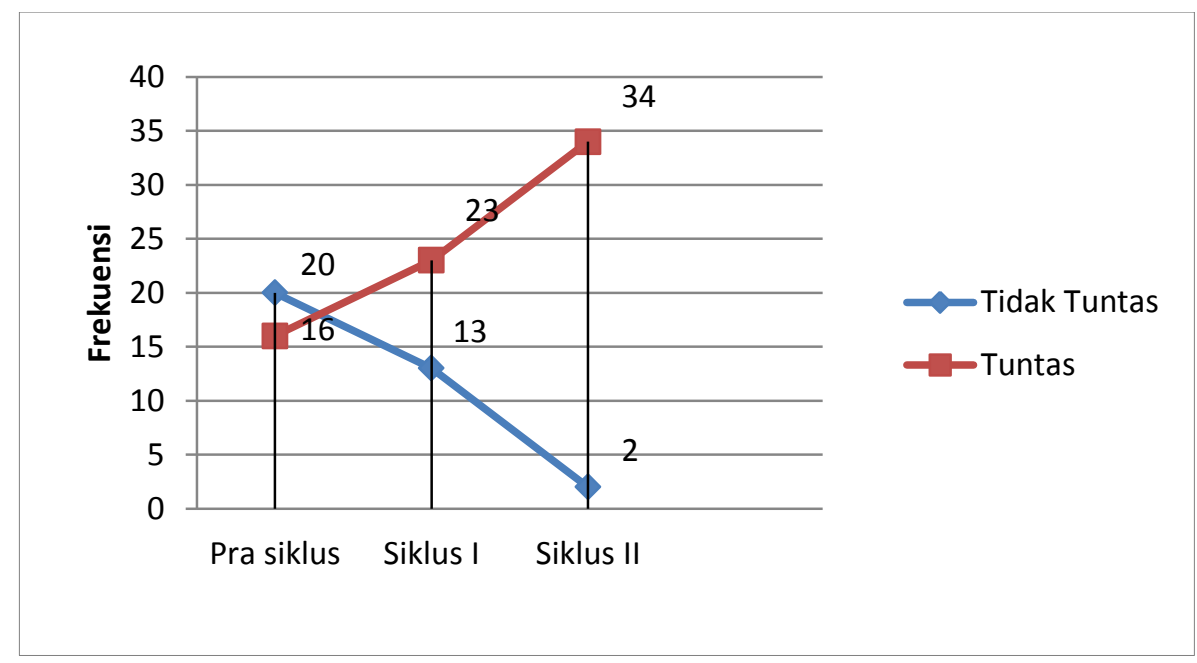

Gambar 1. Peningkatan Hasil Belajar PKn

\section{SIMPULAN}

Berdasarkan hasil penelitian dan pembahasan dapat disimpulkan bahwa pembelajaran PKn mengunakan model active learning tipe role reversal question dapat meningkatkan hasil belajar siswa kelas V SD Negeri 4 Doplang. Hal ini 
ditunjukkan dengan siswa yang memperoleh nilai $\geq 70$ pada siklus I meningkat sebesar 25\% dari kondisi awal 44\% menjadi 69\%. Kemudian siswa yang memperoleh nilai $\geq 70$ pada siklus II mengalami peningkatan $28 \%$ menjadi 97\%. Nilai rata-rata pada siklus I mengalami peningkatan sebesar 8,75\% dari kondisi awal 66,53 menjadi 75,28 pada siklus I kemudian pada siklus II nilai ratarata mengalami peningkatan lagi sebesar $10,97 \%$ menjadi 86,25 .

Peneliti menyarankan hendaknya guru dapat mendorong siswa agar lebih berani dalam mengemukakan pendapat, pertanyaan dan ide yang dimiliki tidak hanya dalam pelajaran PKn saja namun pada mata pelajaran yang lain. Hasil belajar PKn siswa telah mengalami peningkatan setelah diberi tindakan menggunakan model active learning tipe role reversal question, oleh karena itu disarankan kepada siswa agar mempertahankan dan lebih rajin belajar sehingga hasil belajar yang diperoleh selalu baik.

Selain itu, Guru diharapkan dapat menggunakan model active learning tipe role reversal question dalam meningkatkan hasil belajar siswa pada mata pelajaran lain. Adapun bagi pihak sekolah diharapkan memberikan pelatihan kepada guru tentang menerapkan kegiatan pembelajaran yang inovatif seperti model active learning tipe role reversal question. Sekolah juga menyediakan referensi buku tentang pembelajaran yang baik serta sarana penunjang lainnya sehingga guru memiliki wawasan pengetahuan, keterampilan, serta kreativitas dalam menerapkan model-model pembelajaran.

\section{DAFTAR PUSTAKA}

Ari. Samandhi. 2009. Pembelajaran Aktif (Active Learning). Jakarta: Teaching Improvement Worshop Enginering Education Develompment Project.

Baharudin \& Esa Nur Wahyuni. 2009. Teori Belajar dan Pembelajaran. Yogyakarta: Ar-Ruzz Media.

Hiszyam, Zaini. 2008. Strategi Pembelajaran Aktif. Yogyakarta: Insan Madani. 
Hollingsworth, Pat., Gina Lewis. 2008. Pembelajaran Aktif: Meningkatkan Keasyikan Kegiatan Di Kelas. Penerjemah: Dwi Wulandari. Jakarta: Indeks.

Muhammad Thobroni \& Arik Mustofa. 2013. Belajar \& Pembelajaran: Pengembangan Wacana Dan Praktik Pembelajaran Dalam Pembangunan Nasional.Yogyakarta:Ar-Ruzz Media.

Naswatul, Lailah. 2003. Konsep Dasar Active Learning Dan Relevansinya Dengan Pengajaran Muhadatsah. Yogyakarta: Universitas Islam Negeri Yogyakarta.

Hamalik, Oemar. 2006. Proses Belajar Mengajar. Bandung: Bumi Aksara.

Permendiknas No.22 Tahun 2006 tentang Standar Isi untuk Satuan Pendidikan Dasar dan Menengah Dasar.Diakses dari http://bnsp- indonesia. org/ id/? page_id=103 pada tanggal 28 Januari 2016, jam 15.36 WIB.

Silberman, Mel. 2007. Active Learning: 101 Strategi Pembelajaran Aktif. Penerjemah: Sarjuli. Yogyakarta: Insan Madani.

Suharsimi, Arikunto. 2007. Penelitian Tindakan Kelas. Jakarta: Bumi Aksara.

Sudjana, Nana. 2011. Penilaian Hasil Proses Belajar Mengajar. Bandung: PT Remaja Rosda Karya.

Ubaedillah, A., Rozak, Abdul. 2013. Pendidikan Kewarganegaraan (Civic Education): Pancasila, demokrasi, hak asasi manusia dan masyarakat madani. Jakarta: ICCE UIN Syarif Hidayatullah

Undang-Undang Republik Indonesia Nomor 20 tahun 2003 Tentang Sistem Pendidikan Nasional. Yogyakarta: Pustaka Pelajar 